\title{
Gain of Chromosome 2p
}

National Cancer Institute

\section{Source}

National Cancer Institute. Gain of Chromosome 2p. NCI Thesaurus. Code C36439.

A cytogenetic abnormality that refers to the duplication of all or part of the short arm of chromosome 2. 